\title{
Interpretación de la ley penal
}

Luis Miguel Bramont-Arias Torres.

Abogado egresado de la Pontificia Universidad Católica del Perú.

Master en Ciencias Penales y Doctorando en la Universidad de Barcelona.

\section{I.- Diferencia entre Norma y Ley.}

Debemos partir de la distinción entre norma y ley. La norma jurídica debe entenderse como la regla de conducta en un determinado tiempo y lugar, teniendo en cuenta los valores predeterminados según la cultura-; señala la obligación de hacer o no hacer algo, cuyo fin es el cumplimiento de un precepto -la ley-. Con las normas el Estado instruye pautas de conducta y, por tanto, con ellas no prohíbe o manda resultados, sino sólo conductas. Es decir, la norma señala cuál es el valor del sistema, qué es lo que protege; nos da a conocer de qué forma no se debe resolver un conflicto dejando abierta la posibilidad de que éste sea resuelto mediante diversas fórmulas. La norma jurídica, se convierte entonces en un nexo entre la conducta humana y el mundo de los valores que defiende la sociedad. En el mismo sentido, el profesor Bustos Ramírez ${ }^{1}$ refiere que el origen de la norma penal en un Estado Democrático de Derecho surge desde la base social como resultado de un juego interactivo de los sujetos que llevan dentro de un conflicto a un compromiso entre las partes.

La norma jurídica es diferente al concepto de ley dado que está por encima de ella; la ley es un simple vehículo que sirve para plasmar los valores que recogen las normas dentro del ordenamiento jurídico. La norma es un concepto abstracto cuya plasmación concreta se hace a través de la ley; por tanto, no existe la estructura de la norma jurídica sino, la estructura de la ley; lo que se plasmaría de la siguiente manera: $S \ddagger C$, donde " $S$ " sería el supuesto de hecho que, de producirse en la realidad desencadenaría una consecuencia " $C$ ", es decir una consecuencia jurídica. Este esquema establece que, al realizar un individuo una conducta relevante para el ordenamiento jurídico, éste reacciona de una forma determinada, dado el carácter de la acción que se ha realizado. Otro punto de distinción entre la norma y la ley surge en cuanto al destinatario, una se dirige al Estado mientras que la otra a los ciudadanos; en lo que se refiere a su finalidad son igualmente diferentes pues, la norma indica cómo "debe ser" y la ley indica cómo "es". Además, debemos decir que, cada ley penal encierra dos tipos de normas: Primaria, dirigida a los ciudadanos -la forma en que deben comportarse- y, Secundaria, dirigida al órgano jurisdiccional, ordenándole que aplique la sanción dispuesta para el caso concreto.

No podemos dejar de señalar que esta distinción, en la actualidad, en los diversos textos jurídicos se ha ido perdiendo $y$, se está utilizando indistintamente los términos "norma" y "ley".

\section{II.- La interpretación.}

Habiendo establecido que el contenido de la ley es la norma ${ }^{2}$, debemos proceder más allá, a la interpretación ${ }^{3}$ de la ley en sí.

En términos genéricos podemos decir que, la interpretación es una operación intelectual por

1 Bustos Ramírez, Juan y Hormazábal Malarée, Hernán.- “Lecciones de Derecho Penal”, Vol I, Editorial Trotta, Madrid, 1997, p. 36.

2 Puede existir una norma sin ley, pero jamás una ley sin norma. En este sentido, el profesor Carlos Santiago Nino nos dice: "Muchas veces las normas no se verbalizan, sino que se presuponen explícitas cuando se reacciona en cierto sentido frente a determinadas circunstancias. Así ocurre con las normas consuetudinarias y en parte también con las jurisprudenciales. Para que sea verdad, por ejemplo, que entre los comerciantes rige una norma que prescribe considerar el pago dentro de los 30 días como pago al contado, no es necesario que alguien haya pronunciado la oración: "el pago dentro de los 30 días a partir de la operación debe ser considerado como pago al contado". Basta con que los comerciantes reaccionen de igual forma ante ambas modalidades de pago y critiquen a los que no lo hagan. (...) Ello permite considerar las normas como el significado de ciertas oraciones, así como las proposiciones constituyen el significado de otras"; en: "Introducción al Análisis del Derecho", $8^{\circ}$ edición, Editorial Ariel S.A., Barcelona, 1997, p.245.

3 De acuerdo al Diccionario Jurídico Usual del Dr. Guillermo Cabanellas, la interpretación jurídica por excelencia pretende descubrir para sí mismo (comprender) o para los demás (revelar) el verdadero pensamiento del legislador o explicar el sentido de una disposición. 
medio de la cual se busca establecer el sentido de las expresiones utilizadas por la ley. Para determinar los supuestos contenidos en ella y, consecuentemente, su aplicabilidad al supuesto de hecho que se le presenta al intérprete. Tal como nos dice el profesor Marcial Rubio : “ (...) el problema de la interpretación jurídica aparece cuando el que quiere decir la norma jurídica aplicable, no queda lo suficientemente claro a partir de la aplicación de la teoría de las fuentes y del análisis lógico-jurídico interno de la norma. Este problema de interpretación puede surgir del texto mismo (es oscuro en sí), o de su aplicabilidad a un caso concreto (el texto normativo es claro pero no se puede saber con claridad su significado a partir de los matices fácticos del caso al que se quiere aplicarla)".

\section{III.- Caracteres generales de la ley.}

Antes de entrar de lleno a la interpretación de la ley penal debemos recordar los caracteres que tiene la ley:

a) Exclusiva: Se respeta el principio de reserva de ley, especialmente en materia penal. Es decir, se establecen en forma específica y taxativa los hechos que pueden hacer surgir la pretensión punitiva del Estado, los medios, los modos, la medida de represión y los límites dentro de los cuales puede desarrollarse la actividad jurisdiccional.

b) Obligatoria: Al cumplirse con los requisitos de la promulgación y publicación todos deben acatar la ley, lo cual deja de lado la costumbre.

c) Irrefragable: En principio no se puede contrarrestar la ley, sólo por excepción puede ser modificada o derogada por otra ley (posterior).

d) Igualitaria: Se aplica a todas las personas en igual forma, siempre y cuando los sujetos se encuentren en la misma situación, por ejemplo: no se puede tratar en un proceso en igual forma a u sujeto común que a un Ministro de Justicia, él último tiene una serie de privilegios conforme el rol que cumple dentro del Estado. Todo esto es conforme a la Constitución Política del Estado $y$, salvo casos expresamente regulados en ella o en leyes especiales. Por ejemplo: Art. $93^{\circ}$ de la Constitución concordado con el art. $10^{\circ}$ del Código Penal, respecto de los congresistas, ya que no pueden ser detenidos por sus atribuciones especiales ${ }^{5}$.

\section{IV.- La ley penal.}

Luego de haber tratado los caracteres generales de la ley, nos centraremos en la ley penal. La ley penal en su aplicación debe respetar los lineamientos del principio de legalidad, donde como sabemos la ley tiene que ser previa, estricta y escrita. El principio de legalidad también incluye la reserva de ley, es decir solo mediante ley se puede crear los delitos y, como sabemos éstas sólo pueden ser dadas por el Poder Legislativo. Las exigencias constitucionales plantean un límite ulterior y de primer nivel (interpretación conforme a la Constitución).

Una vez que ha surgido la ley penal, es necesario interpretarla, "comprender" lo que dice en abstracto, para ver si se puede aplicar al caso concreto. Como hemos dicho anteriormente, La interpretación es la operación mental que tiende a establecer la voluntad de la ley, ya que, la ley en cuanto es promulgada adquiere una voluntad soberana $y$, su obligatoriedad es tal en cuanto traduce esa voluntad.

Debemos distinguir entre la voluntad de la ley y la voluntad del legislador porque, el intérprete no debe investigar lo que el legislador quiere, sino aquello que en la ley aparece objetivamente querido; esto se basa en que la ley no surge de una individualidad sino de cuerpos colegiados $y$, puede ser muy diverso el espíritu que ha determinado el voto en idéntico sentido, por parte de los integrantes de esa mayoría. De aquí entonces que, la actividad

4 Rubio Correa, Marcial.- "El Sistema Jurídico - Introducción al Derecho”, $5^{\circ}$ edición, Colección de Textos Jurídicos de la Pontificia Universidad Católica del Perú, Fondo Editorial, Lima, 1991, p.266.

5 Constitución Política del Perú: Artículo $93^{\circ}$.- Los congresistas representan a la Nación. No están sujetos a manda to imperativo ni a interpelación.

No son responsables ante autoridad ni órgano jurisdiccional alguno por las opiniones y votos que emiten en el ejercicio de sus funciones.

No pueden ser procesados ni presos sin previa autorización del Congreso o de la Comisión Permanente, desde que son elegidos hasta un mes después de haber cesado en sus funciones, excepto por delito flagrante, caso en el cual son puestos a disposición del Congreso o de la Comisión Permanente dentro de las veinticuatro horas, a fin de que se autorice o no la privación de la libertad y el enjuiciamiento.

Código Penal: Artículo 10'.- La Ley penal se aplica con igualdad. Las prerrogativas que por razón de la función o cargo se reconocen a ciertas personas habrán de estar taxativamente previstas en las leyes o tratados internacionales. 
de un magistrado no consiste en una simple aplicación de la ley penal conforme a su propia letra. Pronunciarse sobre si el hecho cometido es un delito $y$, si éste presenta caracteres que permitan aplicarle un determinado nomen juris, reclaman en el magistrado el conocimiento de la ley para el efecto de una aplicación inteligente de la misma. El Juez no es el dueño de la justicia sino su administrador. Es decir, si bien el Poder Legislativo tiene en sus manos la creación de la ley, los magistrados participan en el proceso de desarrollo de la misma $\mathrm{y}$, por tanto, tienen una función creadora al momento de su aplicación en cada caso concreto.

Se dice que las leyes penales deben ser claras, para de esta forma evitar que se dé la interpretación, pero, esto es falso, ya que todas las leyes deben ser interpretadas, en realidad, en nuestro concepto, no existen leyes que se pueden calificar como cien por ciento claras. Así, el profesor Carlos Santiago Nino : "El significado de las oraciones esta determinado por el significado de las palabras que la integran y por el ordenamiento sintáctico de ellas. En muchas ocasiones las palabras usadas en una oración plantean problemas en cuanto a la determinación de su significado, y en otras el vínculo sintáctico entre los términos de la oración da lugar a equívocos. De ello se infiere que muchas veces no es sencillo determinar qué proposición corresponde a una oración del lenguaje"

El derecho es la voluntad del Estado, que se manifiesta por medio de las palabras que conforman la ley, puede darse entonces, como hemos constatado más de una vez que, las leyes sean ambiguas y defectuosas, que tengan diversos significados según el contexto en el que se encuentren o en relación con otras disposiciones, $\mathrm{o}$ bien con el uso común o con el técnico.

Debemos tener como premisa: La interpretación de la ley penal siempre es necesaria, no es un problema que dependa de sí el texto es claro o es oscuro, sino que surge de la abstracción de la ley y la necesidad de poder subsumir dentro de ellas situaciones concretas de aplicabilidad. Es un problema de la Teoría General del Derecho, por eso sólo cabe examinar algunos aspectos específicos del derecho penal:

\section{En relación al origen y por los sujetos que la realizan:}

a) La interpretación auténtica: Es aquella que realiza la propia ley. Existen leyes, frecuentemente, sobre las cuales cabe dudar acerca del mensaje que quiso transmitir porque, se sospecha que no se eligieron adecuadamente, tanto las palabras como su ordenación sintáctica, por lo cual se debe dar una segunda ley interpretativa de la primera determinando su real contenido. Esto ha surgido debido a que se han presentado una serie de casos, en los el legislador ha emitido una ley con una voluntad totalmente diferente a la que se desprende de la ley. La ley interpretativa, también puede presentarse en las situaciones en las que se debe aclarar o establecer el significado de un determinado término, por ejemplo, el artículo $425^{\circ}$ del Código Penal $^{7}$, en el cual se establece quienes son considerados funcionarios y servidores públicos, aunque ello no agota la labor interpretativa, ya que, surge la necesidad de interpretar la ley interpretativa.

La ley interpretativa es retroactiva, porque se limita a aclarar la voluntad contenida en la ley interpretada. Si en algún momento se aparta de las disposiciones pre-existentes, no será, propiamente, una ley interpretativa $\mathrm{y}$, será obvio que no podrá retrotraer sus efectos más gravosos, en vista al quebrantamiento que sufriría el principio de legalidad (nullum crimen sine previa lege penale).

La interpretación auténtica puede ser contextual o posterior; es contextual cuando surge en el mismo momento que la ley. Por ejemplo: los títulos y los epígrafes.

Cabe preguntarse si la exposición de motivos que surge con la misma ley puede ser calificada dentro

6 Santiago Nino, Carlos.- "Introducción al Análisis del Derecho", $8^{\circ}$ edición, Editorial Ariel S.A., Barcelona, 1997, p.259

7 Código Penal: Artículo $425^{\circ}$.- Se consideran funcionarios o servidores públicos:

1. Los que están comprendidos en la carrera administrativa.

2. Los que desempeñan cargos políticos o de confianza, incluso si emanan de la elección popular.

3. Todo aquél que independientemente del régimen laboral en que se encuentra, mantiene vínculo laboral o contractual de cualquier naturaleza con entidades u organismos del Estado y que en virtud de ello ejerce funciones en dichas entidades $u$ organismos.

4. Los administradores y depositarios de caudales embarcados o depositados por autoridad competente, aunque pertenezcan a particulares.

5. Los miembros de las Fuerzas Armadas y Policía Nacional.

6. Los demás indicados por la Constitución Política y la ley. 
de este contexto, en nuestro concepto no, ya que no expresa exactamente el pensamiento legislativodado que en la formación de leyes intervienen muchas personas-. Es posible que, se presente una situación en la cual surja una contradicción entre la exposición de motivos y el texto legal, en cuyo caso prevalecerá el texto legal. Por ejemplo: conforme lo señalado en la exposición de motivos, plasmado en los artículos VII del Título Preliminar y el artículo $11^{\circ}$ del Código Penal, queda proscrita toda forma de responsabilidad objetiva, parece entrar en contradicción con el art. $123^{\circ}$ del mismo cuerpo legal ${ }^{8}$. Por otro lado, en términos genéricos, cómo se podría interpretar el art. IX del Título Preliminar en relación con el art. $29^{\circ}$ del Código Penal ${ }^{9}, 10$, si en el primero, se señala el fin resocializador de la pena $y$, en el segundo, se establece la cadena perpetua.

La interpretación auténtica es posterior cuando se utiliza una nueva ley para aclarar las oscuridades de la ley anterior, constituye una nueva norma legal, ésta se da debido a la importancia de la materia. En este grupo no debemos incluir las denominadas $F e$ de erratas, ya que, éstas se deben limitar a corregir los errores de impresión o expresión que suelen aparecer en el texto legal y, que razonablemente no ejercen ninguna influencia sobre la manifestación de la voluntad de la ley -en la actualidad se está dando un mal uso de esta técnica, creando y ampliando supuestos dentro de las leyes-.

b) La interpretación judicial: Es la realizada por los órganos jurisdiccionales, Jueces o Salas Penales. Esta surge a través de sus decisiones, sentencias y acuerdos. Para llegar a esta interpretación los magistrados tienen en cuenta la interpretación legislativa, si existe, y la doctrinal, así como su propio criterio, resultando una interpretación sui generis ${ }^{11}$. Toda interpretación implica una interacción entre el sujeto intérprete y el objeto interpretado, por lo tanto, no es posible aplicar el derecho en forma "neutra"; es decir, el Juez nunca infiere una decisión sólo de la ley, sino que llega al caso siempre con un determinado preconcepto, establecido principalmente por la tradición y las circunstancias.

A diferencia de la interpretación auténtica, ésta sólo obliga luego de haberse juzgado y sentenciado un proceso y, sólo se refiere a casos de la misma especie; por ejemplo, cuando una persona ha denunciado ante los órganos jurisdiccionales un delito de usurpación que ha sucedido hace cinco años, en el que el sujeto activo todavía se encuentra dentro del inmueble; para algunos magistrados el delito ya prescribió y para otros no, esto depende de sí se considera al delito de usurpación como un delito continuado o no, lo cual tiene mucha importancia para determinar desde cuando comienza a correr el plazo de prescripción.

El silencio, la oscuridad, la contradicción o la insuficiencia de la ley no exime al Juez del deber de interpretarla y observarla. Esto en materia penal está sujeto a ciertas limitaciones, principalmente en lo referido al principio de legalidad.

No debemos dejar de mencionar que los magistrados desarrollan el Derecho en la medida que lo aplican ${ }^{12}$. En este sentido, el profesor Roxin ${ }^{13}$ señala: “Actualmente hay un acuerdo unánime en

8 Código Penal: Artículo VII del Título Preliminar.- La pena requiere de la responsabilidad penal del autor.

Queda proscrita toda forma de responsabilidad objetiva.

Artículo $11^{\circ}$.- Son delitos y faltas las acciones u omisiones dolosas o culposas penadas por la ley.

Artículo $123^{\circ}$.- Cuando el agente produzca un resultado grave que no quiso causar, ni pudo prever, la pena será disminuida prudencialmente hasta que corresponda a la lesión que quiso infringir.

9 Código Penal: Artículo IX del Título Preliminar.- La pena tiene función preventiva, protectora y resocializadora. Las medidas de seguridad persiguen fines de curación, tutela y rehabilitación.

Artículo $29^{\circ}$.- La pena privativa de libertad puede ser temporal o de cadena perpetua. En el primer caso tendrá una duración mínima de 2 días y una máxima de 35 años.

10 Cabe aclarar que el art. $29^{\circ}$ del Código Penal fue modificado por el Dec.Leg. $\mathrm{N}^{\circ} 895$ el 23 de mayo de 1998 y, que dicho decreto legislativo ha sido recientemente derogado por la Sentencia del Tribunal Constitucional $\mathrm{N}^{\circ} 010-2002-\mathrm{AI} / \mathrm{TC}$ de fecha 03 de enero del 2003.

11 La Ley Orgánica del Poder Judicial señala entre las atribuciones de la Sala Plena de la Corte Suprema: Artículo $80^{\circ}$ núm. 4: Sistematizar y difundir la jurisprudencia de las Salas Especializadas de la Corte Suprema y disponer la publicación trimestral de las Ejecutorias que fijen principios jurisprudenciales que han de ser de obligatorio cumplimiento en todas las instancias judiciales.

12 Vid. Baldó Lavilla, Francisco: "(...) Los tribunales desarrollan el Derecho en la medida que lo aplican. Y ello en tanto que en nuestro modelo constitucional son los destinatarios directos de la competencia primaria de "aplicación de la ley". En efecto, así como no se puede dudar que en nuestro modelo constitucional el legislador posea la competencia primaria legiferante, así tampoco cabe duda que los tribunales posean la competencia primaria de "aplicación de la ley" ¿Supone ello que actúen en 
el sentido de que esa concepción mecanicista del juez es impracticable. Todos los conceptos que emplea la ley (con la excepción de las cifras, fechas, medidas y similares) admiten en mayor o menor medida varios significados. Y ello sucede no sólo en los conceptos normativos (...) sino también en los conceptos legales ampliamente descriptivos (...). Por el contrario, el Juez siempre tiene que elegir entre diversas posibilidades de significado, y esa actividad creadora que se realiza según determinadas reglas es lo que se denomina interpretación".

c) Interpretación doctrinal o privada: Es la mantenida por los juristas y estudiosos del derecho en sus obras específicas. Evidentemente no resulta vinculante pero su influencia es mayor de lo que habitualmente se cree.

Por ejemplo, durante años, la jurisprudencia mantuvo tesis muy estrictas en materia de la relación de causalidad entre la conducta y su resultado -teoría de la equivalencia de condiciones, que gira entorno a la conducta sine qua non- lo que fue profundamente criticado por la doctrina y ha determinado una evolución jurisprudencial hacia la progresiva aplicación de teorías doctrinales modernas. Determinándose que la relación de causalidad requiere de la moderna teoría de la imputación objetiva para un correcto entendimiento de la Teoría del Delito (creación o aumento de un riesgo más allá de los límites permitidos por la ley, observándose que siempre se debe estar dentro del ámbito de aplicación de la norma).

Dado que, los juristas no se ven con la premura de resolver un caso y que, se desarrollan con mayor independencia respecto de los textos legales, la interpretación doctrinaria tiende a ser, por una parte, más flexible que la judicial y; por otra, más sistemática, esto es, más abstracta, general y unitaria.

Un intercambio entre la interpretación judicial y doctrinaria resulta enriquecedor pues, la primera gana en el contenido de justicia y coherencia si se hace cargo de los progresos experimentados por la ciencia y; la segunda, obtiene de la primera el material al que se aplica sus elaboraciones y preserva de ese modo el realismo de su construcción.

La interpretación no es un método exacto, sino que conduce, la mayoría de las veces, a una decisión entre los múltiples principios interpretativos que entran en discusión y entre las múltiples posibilidades de interpretación.

\section{En relación al método utilizado:}

a) Literal o gramatical: Como sabemos la palabra es el primer vehículo por el que la ley expresa su voluntad. Siguiendo la posición del profesor Hurtado $\mathrm{Pozo}^{14}$ la interpretación no puede ser comprendida como la simple comprensión literal del texto, ya que toda comprensión literal implica una precomprensión confirmada, modificada o completada por el procedimiento de la interpretación.

La ley emplea, en su mayor parte, palabras comunes; en menor grado se vale de términos técnicos $y$, también emplea vocablos de peculiar significación jurídica. Las palabras de la ley se deben entender en su sentido natural y obviamente, según el uso general de las mismas palabras porque, la ley es para el pueblo y, es lógico que el legislador la haya escrito para que sea interpretada por el pueblo con su lenguaje usual; pero, cuando la ley se haya definida expresamente para ciertas materias, se les dará un significado legal. Las palabras técnicas de todas las ciencias o artes se tomarán en el sentido que éstas expresan, a menos que aparezcan claramente que se han tomado en sentido diverso. Así, el profesor Marcial Rubio ${ }^{15}$ nos dice: “Para el método literal, el procedimiento de interpretación del que quiere decir la norma consiste en averiguar lo que ella denota mediante el uso de las reglas lingüísticas propias al entendimiento común del

cierto sentido como co-legisladores? Ciertamente. Se admite en nuestros días mayoritariamente que siendo como es la aplicación del derecho -esto es la actualización de la norma en atención al caso concreto- función encomendada a los tribunales, el cumplimiento de esta labor obliga a ir más allá de la pura y neutra construcción de silogismos "formales". Ello supone el reconocimiento actualmente aceptado de que la aplicación de la ley no es un proceso meramente lógico, sino que exige regularmente de los operadores jurídicos la formulación de múltiples valoraciones"; en: "Política Criminal y Nuevo Derecho Penal" (Libro homenaje a Klaus Roxin), Editorial Bosch, Barcelona, 1997, ps. 360-361.

13 Roxin, Claus.- "Derecho Penal - Parte General”, Tomo I: Fundamentos. La estructura de la Teoría del Delito, traducción de la $2^{\circ}$ edición alemana, Editorial CIVITAS, Madrid, 1997, p.147.

14 Hurtado Pozo, José.- "Manual de Derecho Penal - Parte General", $2^{\circ}$ edición (reimpresión), Editorial Distribuidora de Libros S.A. (EDDILI), Lima, 1997, p.181.

15 Rubio Correa, Marcial.- “El Sistema Jurídico - Introducción al Derecho”, $5^{\circ}$ edición, Colección de Textos Jurídicos de la Pontificia Universidad Católica del Perú, Fondo Editorial, Lima, 1991, p. 288. 
lenguaje escrito en el que se halla producido la norma, salvo que los términos utilizados tengan algún significado jurídico específico y distinto del común, en cuyo caso deberá utilizarse este último cuando proceda hacer tal cosa."

Por ejemplo: el término "reincidencia" de acuerdo a su significado vulgar consiste en la repetición de un acto pero, dentro del lenguaje del derecho se refiere al que comete un delito después de haber cumplido su sentencia condenatoria.

La interpretación gramatical no es suficiente, ya que las leyes no se deben interpretar de manera excesivamente formalista, sino atendiendo a su voluntad. Sin embargo, por imperativo del principio de legalidad, la interpretación gramatical opera como límite -y en tal medida es necesaria- de otros métodos que la complementan y que no podrán desbordar del tenor literal de los términos legales.

Por ejemplo: el artículo $189^{\circ}$ núm. 2 del Código Penal $^{16}$ está referido al delito de robo agravado, establece como agravante que el hecho se cometa durante la noche. Gramaticalmente "la noche" significa la parte del día en que el sol está por debajo del horizonte, tiempo caracterizado por la oscuridad. Desde esta interpretación literal, deberían agravarse las penas de todos los delitos cometidos durante tal período; sin embargo, la jurisprudencia y la doctrina han determinado reiteradamente que para la aplicación de tal agravante no basta con que sea de noche, sino que el autor debe haberse aprovechado de la oscuridad para obtener con ello una mayor facilidad para cometer el delito. Pero, acaso esto nos podría llevar a sancionar como delito de robo agravado el comportamiento que realiza un sujeto que se apodera de un bien mueble con violencia, cuando se encuentra dentro de un vagón de tren a las cinco de la tarde, justo cuando el tren esta cruzando un túnel y, se produce la oscuridad. En nuestra opinión, no existiría en este supuesto delito de robo agravado, únicamente hay un robo porque, la agravante se configurará si es de noche (de acuerdo a las horas) y, además, está oscuro.

b) Interpretacion logica o teleol6gica: Propone conocer la voluntad de la ley con arreglo al fin perseguido. Así, el profesor Silfredo Hugo Vizcardo ${ }^{17}$ señala: "(...) la interpretación teleológica no se detiene en el mero estudio del tenor literal de las normas escritas, sino, que partiendo de tal, lo trasciende para buscar la verdad legislada a la luz de la finalidad de la ley misma, particularmente el bien jurídico por ella tutelado". Para lograr esto se deben analizar ciertos elementos como:

b.1) Racional: Observa la razón de ser del precepto, vale decir, los fines sociales que persigue a fin de comprender su mandato. Como el derecho penal apunta a la defensa de los bienes jurídicos, uno de los medios más adecuados para captar el alcance de sus normas es indagar cuál es el bien jurídico bajo protección en cada caso.

b.2) Sistemático: Se debe tomar en consideración todo el conjunto de leyes, por sus principios básicos, por su orientación doctrinal y en orientación a todas las disposiciones que se tratan de esclarecer. Por ejemplo: cuando el Código Penal sanciona el delito de parricidio ${ }^{18}$, puede resultar útil recurrir al Código Civil para determinar las calidades del ascendiente, descendiente, cónyuge o concubino.

b.3) Histórico: Comprende el proceso que ha seguido el precepto hasta convertirse en ley. En este sentido, tiene valor las discusiones y debates que se han producido en el seno del Congreso de la República antes de su promulgación, incluso los proyectos iniciales que dieron origen a su existencia. También se deben tener en cuenta las exposiciones de motivos y demás documentos que hayan servido de base.

b.4) El elemento comparativo extranjero: Consiste en la comparación de nuestras disposiciones de derecho positivo con otras análogas pertenecientes a países extranjeros; frecuentemente se dan casos en los que la legislación nacional o una parte de ella, encuentre su base o inspiración en la legislación extranjera. Por ejemplo: la influencia del Código Penal Alemán respecto de nuestro Código Penal.

16 Código Penal: Artículo $189^{\circ}$.- La pena será no menor de diez ni mayor de veinte años, si el robo es cometido: ... 2.- Durante la noche o en lugar desolado.

17 Hugo Vizcardo, Silfredo.- "Derecho Penal General - Fundamentos Generales de la Teoría de la Ley Penal", Pro Derecho Instituto de Investigaciones Juridicas, Lima, 2001, p. 166-167.

18 Código Penal: Artículo 107\%.- El que, a sabiendas, mata a su ascendiente, descendiente, natural o adoptivo, o a su cónyuge o concubino, será reprimido con pena privativa de libertad no menor de quince años. 
b.5) El elemento extrapenal: Se incluye aquí el elemento político social que motivo la ley. El intérprete no debe olvidar que el derecho sólo se produce por ley; pero que, para interpretarla hay que acudir también a las normas de cultura del país. Por ejemplo: la regulación de la figura del "aborto ético y eugenésico", el establecimiento de este delito fue fuertemente debatido pues, se enfrentaron dos grupos: por un lado, la iglesia exigiendo que se sancione el aborto por eliminar una vida y; por otro, el movimiento feminista que sostenía su despenalización por entender que la mujer puede disponer íntegramente de su cuerpo $y$, dado que, el feto esta dentro de ella, tiene amplia libertad de disposición. Frente a esto, nuestro Código Penal, en su artículo $120^{\circ}$, estableció la figura del aborto ético y eugenésico pero, de tal forma que ambas partes se calmaran; por un lado, al establecerlo como delito la Iglesia se conformó y, por otro, al imponer una pena privativa de libertad no mayor de tres meses, el movimiento feminista lo aceptó pues, conociendo nuestra realidad jurídica, este delito siempre prescribiría -el delito quedaría sin sanción-, dado que, nuestro proceso penal es demasiado lento.

b.6) El elemento extrajurídico: Pretende lograr el esclarecimiento de los términos y palabras de procedencia extraña a la jurídica que concluyen en la redacción de la ley. Por ejemplo: los términos "anomalía psíquica", "grave alteración de la conciencia", "alteraciones en la percepción" utilizados en el artículo $20^{\circ}$ núm. 1 del Código Penal ${ }^{19}$, deben ser interpretados de acuerdo a puntos de vista médicos, sociológicos y criminológicos.

Más que consideraciones lógicas, son las teleológicas las que juegan un rol principal. La interpretación de una ley debe estar en armonía con la finalidad y representación que de la justicia posea el ordenamiento jurídico, allí donde sea posible. Así pues, la interpretación debe elegir un significado que se acerque en la mayor medida posible a la idea de justicia dominante en la comunidad ${ }^{20}$. Pero, no debemos olvidar que nuestro Derecho penal responde a una verdad legal -obtenida durante un proceso judicial, el que debe respetar los procedimientos establecidos por la ley- que no siempre es justa pero, debe tender a ella.

\section{En relación a los resultados:}

a) La interpretación es declarativa: Surge cuando existe una coherencia entre la letra de la ley y la voluntad de la misma; en otras palabras, cuando el sentido de la interpretación gramatical coincide con la interpretación teleológica. Así, el Maestro Bramont Arias"1 : "La interpretación meramente declarativa se resuelve en una exacta coincidencia entre la letra y el espíritu de la ley, sin que el alcance de ésta se amplíe o restrinja. Precisa de entre otros varios significados (indeterminados o ambiguos) de la expresión, aquél que responde exactamente a la voluntad de la ley. La mayor parte de las disposiciones legales son dóciles a la interpretación declarativa. Esta, casi no demanda esfuerzo. Por eso se ha llegado a decir in claris cessat interpretatio, aunque siempre hay ésta, como trabajo intelectual de comprender el significado del texto.

b) La interpretación restrictiva: Surge cuando la palabra de la ley excede la voluntad de la misma $y$, por tanto, se debe reconducir. Por ejemplo: el artículo $147^{\circ}$ del Código Penal ${ }^{22}$, sobre sustracción de menor, establece que la persona actúe mediando relación parental, cuál es esta relación, debemos entonces interpretar en forma restrictiva este concepto. Otro ejemplo, lo encontramos en el artículo $126^{\circ}$, el cual señala responsabilidad sólo sobre el sujeto que omitió prestar socorro a una persona que ha herido o incapacitado, poniendo en peligro su vida o su salud, no se incluye a la persona que creó la situación de peligro para la persona.

19 Código Penal: Artículo $20^{\circ}$.- Esta exento de responsabilidad penal:

1.- El que por anomalía psíquica, grave alteración de la conciencia o por sufrir alteraciones en la percepción, que afectan gravemente su concepción de la realidad, no posea la facultad de comprender el carácter delictuoso de su acto o para determinarse según esta comprensión.

20 Zippelius, R.- “Legitimation im demokratischen Verfassungstaat", en N. Achterberg (ed), Legitimation des modernen Staates, 1981, el mismo autor: Verfassunskonforme Auslegung von Gesetzen, Bundesverfassungsgerocjt-FS (1976), II, pp. 108.

21 Bramont Arias, Luis Alberto.- "La Ley Penal", Librería Mundial de Roberto Meza Simich y Cía, Lima, 1950, ps. 93-94.

22 Código Penal: Artículo $147^{\circ}$. El que, mediando relación parental, sustrae a un menor de edad o rehúsa entregarlo a quien ejerce la patria potestad será reprimido con pena privativa de libertad no mayor de dos años.

Artículo $126^{\circ}$.- El que omite prestar socorro a una persona que ha herido o incapacitado, poniendo en peligro su vida o su salud, será reprimido con pena privativa de libertad no mayor de tres años. 
c) Interpretación extensiva: Surge cuando se amplia el significado natural de las palabras empleadas, para hacerlas coincidir con la voluntad de la ley. Esto se da porque, pareciera que ciertos supuestos no están incluidos dentro del alcance de la ley, en otras palabras, la ley dice menos de lo que quiere decir. Por ejemplo, cuando el artículo $20^{\circ}$ núm. 3 del Código Penal ${ }^{23}$, referido a la legítima defensa trata el punto de la necesidad racional del medio empleado, no quiere decir que el medio debe ser igual al que usa el agresor sino que, bajo las circunstancias que se han producido, el comportamiento realizado era la única manera de lograr una efectiva defensa. Por ejemplo, si me ataca Mike Tyson no voy a defenderme con los puños, sino con cualquier medio que este a mi alcance para defenderme (una pistola, un cuchillo, una botella, etc.). Otro ejemplo, lo podemos ver respecto del artículo $139^{\circ}$ del Código Penal ${ }^{24}$ (bigamia), el cual establece como supuesto de hecho: "el casado que contrae matrimonio", se puede incluir la hipótesis de que el casado contraiga varios matrimonios.

d) Interpretación progresiva: Es la que atiende a los elementos cambiantes de la cultura, costumbre y de medio social, comprendidos en la ley o supuestos de ella, y evoluciona con ella aún cuando la redacción del precepto permanezca igual. Así, el profesor Velásquez Velásquez ${ }^{25}$ señala: “Teniendo en cuenta que la norma aparece en un determinado medio social, sujeto a cambios y a evoluciones continuas, debe adaptarse a las situaciones que se vayan presentando so pena de tener que modificarla a diario; por ello, es misión del intérprete armonizarla acorde a las transformaciones que se vayan presentando en los ámbitos científicos, jurídico y social. De allí que se le conozca también con la denominación de evolutiva o de histórico- evolutiva, aunque no debe olvidarse que en ninguna circunstancia puede desatenderse el principio del favor lei, es decir que las dudas han de resolverse siempre en beneficio del encartado y no en su contra".

Por ejemplo, el término "bien mueble" incluye ahora a los programas de computadoras (software); en otro aspecto, podemos decir que, el concepto de anomalía psíquica que se manejo hoy en día es sustancialmente diferente del usado hace 20 años.

\section{La Interpretación Analogica:}

En el ordenamiento penal está prohibida la analogía (artículo III del Título Preliminar del Código Penal). Las leyes penales no pueden ser aplicadas a supuestos distintos de aquellos para los que están previstos.

La analogía consiste en aplicar la ley a supuestos no contemplados en ella pero, similares a los que la ley describe. La analogía no es una forma de interpretación de la ley, sino de creación de la misma. La analogía trata de que, una vez interpretada la ley -es decir, una vez establecido los supuestos que contiene-, se extienden sus consecuencias a otros supuestos no contenidos, pero similares o análogos.

La interpretación analogica no entraña la creación de un nuevo supuesto, sino deducir uno de análoga existencia en la ley y previamente autorizado por el contexto de la ley penal, es decir, el legislador ha comprendido que la fórmula casuística empleada no ha podido prever todos los casos. Por ejemplo: el artículo $46^{\circ}$ del Código Penal ${ }^{26}$, sobre las bases para determinar la pena,

23. Código Penal: Artículo $20^{\circ}$.- Esta exento de responsabilidad penal:

(...) 3.- El que obra en defensa de bienes juridicos propios o de terceros, siempre que concurran las circunstancias siguientes:

a) Agresión ilegítima;

b) Necesidad racional del medio empleado para impedirla o repelerla. Se excluye para la valoración de este requisito el criterio de proporcionalidad de medios, considerándose en su lugar, entre otras circunstancias, la intensidad y peligrosidad de la agresión, la forma de proceder del agresor y de los medios de que se disponga para la defensa.

c) Falta de provocación suficiente de quien hace la defensa.

24 Código Penal: Artículo $139^{\circ}$.- El casado que contrae matrimonio será reprimido con pena privativa de libertad no mayor de uno ni mayor de cuatro años.

Si respecto a su estado civil, induce a error a la persona con quien contrae nuevo matrimonio la pena será privativa de libertad no menor de dos mi mayor de cinco años.

25 Velásquez Velásquez, Fernando.- “Derecho Penal - Parte General”, $2^{\circ}$ Edición, Editorial TEMIS S.A., Santa Fe de Bogotá, 1995 p. $118-119$.

26 Código Penal: Artículo $46^{\circ}$.- Para determinar la pena dentro de los límites fijados por la ley, el juez atenderá la responsabilidad y gravedad del hecho punible cometido, en cuanto no sean específicamente constitutivas del hecho punible o modificatorias de la responsabilidad, considerando especialmente:...

Al señalar el artículo $46^{\circ}$ que se debe considerar especialmente ciertas situaciones da a entender que también se deben considerar situaciones que no se encuentre específicamente mencionadas en dicho artículo. 
establece que se tendrán en cuenta los numerales de dicho artículo pero, esta enumeración no es cerrada. Otros ejemplos, los encontramos en los artículos $108^{\circ}$ núm. 4 y $170^{\circ}$ del Código Penal, el primero, referido al delito de asesinato, en el cual encontramos la fórmula: “(...) o por cualquier otro medio capaz de poner en peligro la vida o salud de otras personas"; el segundo, se refiere al delito de violación de la libertad sexual, en el que se utiliza la fórmula “(..) practicar el acto sexual u otro análogo"27.

Conforme nos lo indica el profesor Roxin ${ }^{28}$ : "La prohibición de la analogía plantea la tarea de tener que delimitar la interpretación fiel a la ley, que está permitida, de la analogía creadora de derecho, que está prohibida"

Todos los puntos tratados nos pueden ayudar a interpretar la ley penal pero, en esencia la interpretación de la ley penal es dirigida a la protección de los bienes jurídicos que ha recogido nuestro ordenamiento penal. Por tal razón, debemos tener en cuenta el fin de la ley penal, el cual se centra en evitar que los individuos cometan delitos. Esto tiene relación directa con los fines de la pena, los que se explican de acuerdo a las teorías de la prevención general y especial. Tal como indica el profesor Roxin: existen tres momentos:

1. Prevención general.- la cual tiene dos aspectos, uno positivo enfocado en reforzar los valores de la sociedad y; otro aspecto negativo que consiste en amenazar con una sanción la realización de las conductas establecidas como prohibidas dentro de la sociedad. La prevención general debe aplicarse antes de que se cometa el delito, se quiere motivar al sujeto para que de una $u$ otra forma no realice conductas típicas.

2. Prevención especial.- Se centra en el momento posterior a la comisión de un delito, busca resocializar al delincuente, mediante diversos tratamientos terapéuticos, se quiere hacer comprender al sujeto que su conducta es errada y, que compromete a toda la sociedad, la cual lo requiere como un ser productivo que pueda desarrollarse armónicamente con sus conciudadanos.

3. El límite de la sanción es la teoría retributiva. Es decir, no se debe imponer una sanción por encima del limite de la responsabilidad del sujeto.

Cuando el magistrado tenga en cuenta todos estos aspectos realizará una correcta interpretación de las leyes penales.

\section{Concurso aparente de Leyes.}

Es un problema de interpretación, surge cuando el sujeto activo realiza una acción que podría, aparentemente, ser calificada en más de un tipo penal, cuando en realidad sólo se puede aplicar uno. Tal como dice Carlos Creus ${ }^{29}:$ "(..) el encuadramiento plural se reduce a un encuadramiento único (por eso se dice que el concurso es sólo "aparente"), cuando uno de los tipos en juego desplaza a los otros, con lo cual únicamente queda vigente el tipo desplazante". A esto cabe agregar, conforme el profesor Mir Puig ${ }^{30}$ : "(...) cuando uno o varios hechos son incluibles en varios preceptos penales de los que sólo uno puede aplicarse, puesto que su estimación conjunta supondría un bis in idem. Ello sucede siempre que uno de los preceptos basta por sí solo para aprehender todo el desvalor del hecho o hechos concurrentes".

Conforme resalta el profesor Mir Puig, la decisión de cuándo existe un concurso de leyes (y un solo delito), y no un concurso de delitos, así como, en su caso, la cuestión de qué norma es preferente y cuál debe quedar desplazada, depende de la interpretación de las distintas normas penales en juego. La doctrina con el fin de orientar una correcta interpretación del problema del concurso aparente de leyes, ha dispuesto una serie de

27 Código Penal: Artículo $108^{\circ}$.- Será reprimido con pena privativa de libertad no menor de veinticinco años, el que mata a otro concurriendo cualquiera de las circunstancias siguientes:

(...) 4.- Por fuego, explosión, veneno o por cualquier otro medio capaz de poner en peligro la vida o salud de otras personas. Artículo $170^{\circ}$.- El que con violencia o grave amenaza, obliga a una persona a practicar el acto sexual u otro análogo, será reprimido con pena privativa de libertad no menor de cuatro ni mayor de ocho años.

Si la violación se realiza a mano armada y por dos o más sujetos, la pena será no menor de ocho ni mayor de quince años.

28 Roxin, Claus.- "Derecho Penal - Parte General", Tomo I: Fundamentos. La estructura de la Teoría del Delito, traducción de la $2^{\circ}$ edición alemana, Editorial CIVITAS, Madrid, 1997, p.147.

29 Creus, Carlos.- "Derecho Penal - Parte General", $3^{\circ}+$ edición actualizada y ampliada, Editorial Astrea, Buenos Aires, 1992 , p.287.

30 Mir Puig, Santiago.- "Derecho Penal - Parte General", 5+edición, Impreso por TECFOTO, Barcelona, 1998, p. 675. 
principios como: especialidad, alternatividad, subsidiariedad y consunción.

1) Principio de Especialidad: La regla es que el tipo especial desplaza al tipo genérico, lo cual sucede en los delitos en que hay relaciones de tipos básicos a derivados ${ }^{31}$. El tipo especial realiza obligatoriamente el tipo general pero, no todo hecho que cumple con el tipo general se puede subsumir en el tipo especial. En este sentido el profesor Berdugo $^{32}$ : "(...) el legislador obliga a elegir la norma especial antes que la general, esto es, aquella que presenta todos los elementos de esta última más alguno o algunos específicos". Por ejemplo: el art. $107^{\circ}$ del Código Penal trata el delito de parricidio el cual desplaza al delito de homicidio.

2) Principio de Subsidiariedad: se aplica el tipo subsidiario cuando no se puede aplicar un tipo distinto. Es decir, se da una posición opuesta a la del principio de especialidad, cuando no se puede cumplir con todos los requisitos que establece el tipo especial, se aplicará el tipo general.

En palabras del profesor Mir Puig ${ }^{33}$ : "El principio de subsidiariedad interviene cuando un precepto penal sólo pretende regir en el caso de que no entre en juego otro precepto penal. El primer precepto es entonces subsidiario respecto del segundo y queda desplazado cuando éste aparece (lex primaria derogat legem subsidiariam: la ley primaria deroga la subsidiaria)".

Existen casos en los que el propio tipo penal indica que se aplique de esta manera. Por ejemplo, cuando no se puede adecuar el comportamiento de un sujeto al art. $121^{\circ}$-A (lesiones graves de acuerdo al sujeto activo y pasivo), se tiene que aplicar el art. $121^{\circ}$ (lesiones graves). Pero, el problema crece cuando el Código Penal no indica una disposición expresa, por ejemplo: si una persona entra a una casa mediante el escalamiento con el propósito de hurtar bienes $y$, luego esto no se puede demostrar, no se puede condenar al agente por hurto agravado pero sí, por el delito de violación de domicilio, el cual es en este caso un tipo de carácter subsidiario.

3) Principio de Consunción: Surge cuando el contenido de una acción típica incluye a otro tipo penal -un delito que abarca a otro delito-. El precepto más amplio o complejo absorberá a los que castiguen las infracciones consumidas en aquél. Aunque no siempre resulta fácil determinar si una infracción puede entenderse absorbida por otra. Por ejemplo: si una persona destruye una pared con el propósito de realizar un robo lleva a cabo un delito de daños, incurriría en el artículo $205^{\circ}$ del Código Penal -daños- pero, este tipo queda desplazado por el delito de robo. El profesor Berdugo $^{34}$ aclara: "(...) la absorción solo es posible cuando el desvalor de la conducta es 10 suficientemente pequeño como para no reclamar una pena autónoma, cosa que ocurrirá seguramente cuando la lesión sea constitutiva de una simple falta".

4) Principio de Alternatividad: Puede darse casos en que un tipo se refiere a la misma acción que otro, el desplazamiento se da cuando en uno de los tipos surgen circunstancias particulares que se enuncian respecto de dicha acción. Por ejemplo: en el delito de hurto y de apropiación ilícita sobre un tesoro, constituyen un apoderamiento de cosa ajena ya que el tesoro pertenece en forma parcial al propietario del suelo- pero, dado que, el apoderamiento recae sobre un tesoro se aplica el artículo. $192^{\circ}$ num. 1 -apropiación ilícita de un tesoro-

Este principio sólo se aplica en defecto de los anteriores, es decir cuando no es posible hallar una relación de especialidad, subsidiariedad o consunción. $D_{S}$

31 En general se reconoce que el tipo especial desplazante es aquel que, conteniendo los elementos del general que desplaza, enuncia una forma específica de lesión del bien jurídico (Bacigalupo). Siempre hay una relación conceptual de subordinación entre los tipos (Zaffaroni).

32 Berdugo Gómez de la Torre, Ignacio y otros.- "Lecciones de Derecho Penal - Parte General", 20 edición, Editorial Praxis, Barcelona, 1999, p.309.

33 Mir Puig, Santiago.- "Derecho Penal - Parte General", $5^{\circ}$ edición, Impreso por TECFOTO, Barcelona, 1998, p. 678.

34 Berdugo Gómez de la Torre, Ignacio y otros.- "Lecciones de Derecho Penal - Parte General", $2^{\circ}$ edición, Editorial Praxis, Barcelona, 1999, p.310. 